\title{
ANÁLISE DA ESTRUTURA HORIZONTAL DE UM FRAGMENTO DE FLORESTA OMBRÓFILA MISTA EM FAZENDA RIO GRANDE-PR, NO PERÍODO DE 2000 A 2009
}

\author{
WOYCIKIEVICZ, Antonio Pedro Fragoso ${ }^{1}$ \\ PÉLLICO NETTO, Sylvio ${ }^{1}$ \\ CORAIOLA, Marcio ${ }^{2}$
}

RESUMO: As florestas naturais são ambientes complexos caracterizados por grande variabilidade na composição florística e distribuição das árvores. O conhecimento sobre a estrutura de uma floresta fornece informações que melhoram a compreensão do funcionamento da floresta, bem como ferramentas que permitem o manejo florestal sustentável. O objetivo do trabalho foi avaliar a estrutura horizontal de um fragmento da Floresta Ombrófila Mista por meio dos parâmetros fitossociológicos de Densidade, Dominância, Frequência e Índice de Valor de Importância (VI). O estudo foi baseado na análise de 6 parcelas permanentes de um hectare cada, instaladas na Fazenda Experimental Gralha Azul - PUC-PR, e pertencentes ao projeto PELD, no período de 2000 a 2009. A espécie Myrcia sp. apresentou-se como a espécie com maior densidade (87,67 ind./ha em 2000 e 1,83 ind./ha em 2009) e frequência (52,83\% em 2000 e 58,00\% em 2009), obtendo também o maior VI, com 26,45 em 2000 e 30,02 em 2009. A Canela fedida (Nectandra lanceolata) apresentou a maior dominância $\left(2,7348 \mathrm{~m}^{2} / \mathrm{ha}\right.$ em 2000 e 2,9117 $\mathrm{m}^{2} /$ ha em 2009), seguida pela sassafrás (Ocotea odorifera), com 2,2669 m²/ha em 2000 e 2,7151 m²/ha em 2009. Durante o período de 9 anos, a densidade da floresta diminui de 798,34 ind./ha para 745,83 ind./ha, com um incremento de área basal passando de $32,5182 \mathrm{~m}^{2} /$ ha para $34,0008 \mathrm{~m}^{2} / \mathrm{ha}$. Observou-se redução na densidade da floresta, no entanto, houve aumento na dominância, fato esse devido ao elevado número de indivíduos por hectare e por se tratar de uma floresta secundária, muito alterada no passado por ações de influência antrópica.

Palavras Chave: Parâmetros fitossociológicos. Dominância. Densidade.

SUMMARY: Analysis the horizontal structure of a Mixed Ombrophile Forest's in the Fazenda Rio Grande-PR, between the years 2000 and 2009. Natural forests are complex environments characterized by great variability in their floristic composition and distribution of their trees. The knowledge about a forest's structure provides information that improves the understanding of the forest's functioning as well as tools that enable sustainable forest management. The objective of this study is to evaluate the horizontal structure of a Mixed Ombrophile Forest's fragment taking in consideration the parameters of phytosociological density, dominance, frequency, and the importance value index (VI.). This study was based on the analyses of the information obtained in the Project PELD's database regarding 6 permanent parcels (each one with one hectare) that belong to the Project PELD and are located in the Experimental Farm Gralha Azul - PUC-PR between the years 2000 and 2009. The species Myrcia sp. presented the highest density (87.67 ind./ha in 2000 and 1.83 ind./ha in 2009), frequency (52.83\% in 2000 and 58.00\% in 2009), and the highest VI (26.45 in 2000 and 30.02 in 2009). The species Nectandra lanceolata presented the highest dominance with $2.7348 \mathrm{~m}^{2} /$ ha in 2000 and $2.9117 \mathrm{~m}^{2} /$ ha in 2009 , followed by the sassafras (Ocotea odorifera) with $2.2669 \mathrm{~m}^{2} /$ ha in 2000 and $2.7151 \mathrm{~m}^{2} / \mathrm{ha}$ in 2009 . Besides the Myrcia sp., the Ocotea odorifera, and the Ilex paraguariensis are also among the three most frequent tree species. They are also among the three species of tree that presented the highest VI in this forest. During the research period, there was a reduction in the number of trees in the forest caused mostly by their competition for resources.

Keywords: Parameters of phytosociological. Dominance. Density.

\section{INTRODUÇÃO}

Este estudo representa a continuidade e a ampliação dos estudos ecológicos realizados durante 10

\footnotetext{
${ }^{1}$ Universidade Federal do Paraná

${ }^{2}$ Pontifícia Universidade Católica do Paraná
} 
anos pela equipe do PELD Site 9 - Floresta com Araucária e suas Transições, no âmbito do bioma Mata Atlântica. Trata-se, portanto, de uma proposta científica e de desenvolvimento tecnológico voltado aos estudos ecológicos de longa duração, realizados em unidades experimentais e de observação situadas em áreas públicas e privadas, sendo monitoradas nos seus processos ecológicos por mais de uma década.

As florestas nativas em seu ambiente bastante complexo, têm-se um ecossistema, cujo equilíbrio pode ser facilmente alterado por perturbações expressivas no meio, como ações antrópicas, por exemplo.

As florestas naturais possuem elevada diversidade de espécies e uma grande variação de qualidades em termos econômicos. Assim, os levantamentos estruturais devem abranger pelo menos os seguintes itens: estrutura horizontal, estrutura vertical, estrutura paramétrica e estrutura da regeneração natural.

Vários autores realizaram estudos em remanescentes de Floresta Ombrófila Mista como Rondon Neto et al. (2002), Galvão et al. (1989), Valério et al. (2008), Sanquetta et al. (2001) e Rode et al. (2010). Tais trabalhos procuraram demonstrar a composição da estrutura horizontal dessa tipologia florestal, abordando quais espécies são as mais dominantes, juntamente com sua densidade e frequência e, consequentemente, com seu valor de importância no total da floresta.

No Brasil, as florestas nativas, historicamente exploradas de forma desordenada e com pouco ou nenhuma preocupação com a sustentabilidade para as gerações futuras, são pouco utilizadas as técnicas de manejo florestal e silviculturais (SETPKA, 2008).

Considerando a necessidade por mais estudos que visem orientar o estado de conservação e indicar alternativas a preservação dos fragmentos de Floresta Ombrófila Mista na região Sul do Brasil, o objetivo do presente trabalho foi analisar a estrutura horizontal de um remanescente florestal no período de 2000 a 2009, com destaque a densidade, a dominância, a frequência e ao Valor de Importância das espécies ocorrentes na área.

\section{MATERIAL E MÉTODO}

O trabalho foi realizado em um fragmento de Floresta Ombrófila Mista, localizado na Fazenda Experimental Gralha Azul (PUCPR), município de Fazenda Rio Grande - PR, entre as coordenadas geográficas $25^{\circ} 39^{\prime} 31^{\prime \prime} \mathrm{S}$ e $49^{\circ} 18^{\prime} 32^{\prime \prime} \mathrm{O}$, a uma altitude média de $911 \mathrm{~m}$. O clima na região, segundo a classificação de Köppen, é o do tipo Cfb, caracterizado por um clima temperado propriamente dito. A área aproximada da floresta é de 300 hectares.

Os dados utilizados para realização do presente estudo foram obtidos a partir do banco de dados do Projeto PELD. Para tal foram considerados todos os indivíduos arbóreos com DAP $\geq 10 \mathrm{~cm}$, medidos em 6 parcelas permanentes $(100 \times 100 \mathrm{~m})$. O tamanho das unidades foi obtido a partir de recomendações de Coraiola (1997) e outros autores, que sugeriram parcelas de maior área para levantamentos estruturais e avaliações dos processos dinâmicos em florestas naturais.

No ano de 2000, foi iniciado o primeiro inventário das parcelas. Na ocasião, as parcelas foram demarcadas com a utilização de canos de PVC e o auxílio de trenas, sendo materializadas com piquetes em sub-parcelas de $10 \mathrm{~m}$ x $10 \mathrm{~m}\left(100 \mathrm{~m}^{2}\right)$. As árvores com DAP $\geq 10 \mathrm{~cm}$ foram marcadas, identificadas e mensuradas. A posição de todas as árvores foram demarcadas com coordenadas x e y, dentro de cada subparcela correspondente.

Os inventários subsequentes foram realizados até 2013. Para a avaliação deste trabalho foram considerados o primeiro (2000) e o último ano de medição (2009). Com base no inventário realizado em 2013, foi possível consistir o banco de dados original do projeto, possibilitando a análise mais precisa dos dados coletados no período de interesse (2000 - 2009). 
A estrutura horizontal foi caracterizada por meio da análise dos parâmetros fitossociológicos de densidade (D), dominância (Do), frequência (FR) e valor de importância (VI). Os cálculos foram realizados por parcela e para a floresta como um todo. Para efeito de processamento dos valores relativos, foram considerados apenas os dados referentes ao total da floresta.

\section{RESULTADO E DISCUSSÃO}

Nas Tabelas 1 e 2 são apresentados os valores de densidade, dominância e frequência, em valores absoluto e relativo, e o valor de importância, em valor absoluto, para os anos de 2000 e 2009, respectivamente. Ambas as Tabelas foram organizadas em ordem decrescente de VI.

Tabela 1. Parâmetros fitossociológicos de densidade, dominância, frequência e VI, para o ano de 2000

\begin{tabular}{|c|c|c|c|c|c|c|c|c|}
\hline \multicolumn{2}{|r|}{ Espécies } & \multicolumn{2}{|c|}{ Densidade } & \multicolumn{2}{|c|}{ Dominância } & \multicolumn{2}{|c|}{ Frequência } & \multirow{2}{*}{$\frac{\mathrm{VI}}{\%}$} \\
\hline Nome Popular & Nome científico & Absoluta & $\%$ & Absoluta & $\%$ & Absoluta & $\%$ & \\
\hline Guamirim & Myrcia sp. & 87,67 & 10,98 & 2,1852 & 6,72 & 52,83 & 8,75 & 26,45 \\
\hline Sassafrás & Ocotea odorifera (Vellozo) Rohwer. & 80,67 & 10,10 & 2,2669 & 6,97 & 50,50 & 8,36 & 25,44 \\
\hline Erva Mate & Ilex paraguariensis & 65,33 & 8,18 & 2,4251 & 7,46 & 43,83 & 7,26 & 22,90 \\
\hline Canela Fedida & Nectandra lanceolata & 42,50 & 5,32 & 2,7348 & 8,41 & 31,00 & 5,13 & 18,87 \\
\hline Caingá & Myrcinhatschbachii sp. & 45,83 & 5,74 & 1,4851 & 4,57 & 32,00 & 5,30 & 15,61 \\
\hline $\begin{array}{l}\text { Laranjeira } \\
\text { Brava }\end{array}$ & Gymnanthes concolor Spreng. & 53,00 & 6,64 & 0,9226 & 2,84 & 34,83 & 5,77 & 15,24 \\
\hline Pimenteira & Piper arboreum Aubl. & 36,33 & 4,55 & 1,4216 & 4,37 & 22,34 & 3,70 & 12,62 \\
\hline $\begin{array}{l}\text { Cafezeiro } \\
\text { Bravo }\end{array}$ & Casearia silvestris & 31,17 & 3,90 & 0,8224 & 2,53 & 26,17 & 4,33 & 10,77 \\
\hline Cedro & Cedrela fissilis Vell. & 16,83 & 2,11 & 1,5184 & 4,67 & 15,17 & 2,51 & 9,29 \\
\hline Sapopema & Sloanea lasiocoma K. Schum. & 15,50 & 1,94 & 1,4411 & 4,43 & 14,50 & 2,40 & 8,77 \\
\hline Araucária & Araucaria angustifolia (Bertol.) Kuntze & 12,83 & 1,61 & 1,6996 & 5,23 & 9,17 & 1,52 & 8,35 \\
\hline Guaçatunga & Casearia decandra Jacq. & 24,00 & 3,01 & 0,5667 & 1,74 & 19,17 & 3,17 & 7,92 \\
\hline $\begin{array}{c}\text { Canela } \\
\text { Amarela }\end{array}$ & Nectandra lanceolata Ness et Mart.ex Nees & 12,17 & 1,52 & 1,1993 & 3,69 & 10,50 & 1,74 & 6,95 \\
\hline Guabiroba & Campomanesia pubescens (DC.) O. Berg & 15,67 & 1,96 & 0,7261 & 2,23 & 14,00 & 2,32 & 6,51 \\
\hline Canela Garuva & Nectandra oppositifolia Nees & 7,67 & 0,96 & 1,0455 & 3,22 & 6,00 & 0,99 & 5,17 \\
\hline Pau de Leite & Sapium glandulatum (Vell.) Pax. & 8,67 & 1,09 & 0,6302 & 1,94 & 11,83 & 1,96 & 4,98 \\
\hline $\begin{array}{l}\text { Miguel } \\
\text { Pintado }\end{array}$ & Matayba elaeagnoides Radlk & 8,50 & 1,06 & 0,6800 & 2,09 & 8,17 & 1,35 & 4,51 \\
\hline Bugreiro & Lithraea brasilienses & 8,50 & 1,06 & 0,5453 & 1,68 & 6,67 & 1,10 & 3,85 \\
\hline Caroba & Jacaranda micrantha Cham. & 10,00 & 1,25 & 0,3203 & 0,98 & 8,33 & 1,38 & 3,62 \\
\hline Capoeirão & Turdus leucomelas & 11,33 & 1,42 & 0,2621 & 0,81 & 5,50 & 0,91 & 3,14 \\
\hline Aroeira & Schinus terebinthifolius Raddi & 7,17 & 0,90 & 0,3344 & 1,03 & 6,00 & 0,99 & 2,92 \\
\hline $\begin{array}{l}\text { Guamirim } \\
\text { Miúdo }\end{array}$ & $\begin{array}{c}\text { Myrceugenia campestris (DC.) D. Legrand et } \\
\text { Kausel }\end{array}$ & 7,67 & 0,96 & 0,2930 & 0,90 & 6,17 & 1,02 & 2,88 \\
\hline Jacarandá Liso & Machaerium vestitum Vogel & 7,00 & 0,88 & 0,2276 & 0,70 & 6,33 & 1,05 & 2,62 \\
\hline Maria Mole & Pisonia aculeata L. & 6,67 & 0,84 & 0,1867 & 0,57 & 6,00 & 0,99 & 2,40 \\
\hline Canela Branca & Nectandra membranacea & 4,33 & 0,54 & 0,2845 & 0,87 & 4,17 & 0,69 & 2,11 \\
\hline Carne de Vaca & Clethra scabra Pers & 1,83 & 0,23 & 0,1574 & 0,48 & 8,33 & 1,38 & 2,09 \\
\hline$:$ & $:$ & : & : & : & $:$ & : & : & : \\
\hline$:$ & $:$ & : & $:$ & : & $:$ & : & : & : \\
\hline Total & & 798,34 & 100,00 & 32,518 & 100,00 & 604,01 & 100,00 & 300 \\
\hline
\end{tabular}


Tabela 2. Parâmetros fitossociológicos de densidade, dominância, frequência e VI, para o ano de 2009

\begin{tabular}{|c|c|c|c|c|c|c|c|c|}
\hline \multicolumn{2}{|r|}{ Espécies } & \multicolumn{2}{|c|}{ Densidade } & \multicolumn{2}{|c|}{ Dominância } & \multicolumn{2}{|c|}{ Frequência } & \multirow{2}{*}{$\frac{\mathrm{VI}}{\%}$} \\
\hline Nome Popular & Nome científico & Absoluta & $\%$ & Absoluta & $\%$ & Absoluta & $\%$ & \\
\hline Guamirim & Myrcia sp. & 91,83 & 12,31 & 2,5330 & 7,45 & 58,00 & 10,26 & 30,02 \\
\hline Sassafrás & Ocotea odorifera (Vellozo) Rohwer. & 81,17 & 10,88 & 2,7151 & 7,99 & 52,00 & 9,20 & 28,07 \\
\hline Erva Mate & Ilex paraguariensis & 57,00 & 7,64 & 2,6288 & 7,73 & 39,33 & 6,96 & 22,33 \\
\hline Canela Fedida & Nectandra lanceolata & 39,83 & 5,34 & 2,9117 & 8,56 & 29,50 & 5,22 & 19,12 \\
\hline $\begin{array}{l}\text { Laranjeira } \\
\text { Brava }\end{array}$ & Gymnanthes concolor Spreng. & 56,00 & 7,51 & 1,0296 & 3,03 & 37,00 & 6,54 & 17,08 \\
\hline Caingá & Myrcinhatschbachii sp. & 45,83 & 6,15 & 1,6194 & 4,76 & 32,33 & 5,72 & 16,63 \\
\hline Pimenteira & Piper arboreum Aubl. & 32,00 & 4,29 & 1,5099 & 4,44 & 20,00 & 3,54 & 12,27 \\
\hline $\begin{array}{l}\text { Cafezeiro } \\
\text { Bravo }\end{array}$ & Casearia silvestris & 30,00 & 4,02 & 0,9261 & 2,72 & 25,33 & 4,48 & 11,23 \\
\hline Araucária & Araucaria angustifolia (Bertol.) Kuntze & 13,00 & 1,74 & 1,9491 & 5,73 & 9,33 & 1,65 & 9,13 \\
\hline Guaçatunga & Casearia decandra Jacq. & 24,83 & 3,33 & 0,6749 & 1,98 & 20,34 & 3,60 & 8,91 \\
\hline Cedro & Cedrela fissilis Vell. & 14,67 & 1,97 & 1,5147 & 4,45 & 13,33 & 2,36 & 8,78 \\
\hline Sapopema & Sloanea lasiocoma K. Schum. & 12,50 & 1,68 & 1,4848 & 4,37 & 11,67 & 2,06 & 8,11 \\
\hline $\begin{array}{l}\text { Canela } \\
\text { Amarela }\end{array}$ & Nectandra lanceolata Ness et Mart.ex Nees & 12,17 & 1,63 & 1,3397 & 3,94 & 10,50 & 1,86 & 7,43 \\
\hline Guabiroba & Campomanesia pubescens (DC.) O. Berg & 16,33 & 2,19 & 0,8507 & 2,50 & 14,83 & 2,62 & 7,31 \\
\hline Canela Garuva & Nectandra oppositifolia Nees & 7,17 & 0,96 & 1,1151 & 3,28 & 5,67 & 1,00 & 5,24 \\
\hline $\begin{array}{l}\text { Miguel } \\
\text { Pintado }\end{array}$ & Matayba elaeagnoides Radlk & 8,17 & 1,09 & 0,7230 & 2,13 & 8,00 & 1,41 & 4,64 \\
\hline Caroba & Jacaranda micrantha Cham. & 9,17 & 1,23 & 0,3364 & 0,99 & 7,67 & 1,36 & 3,58 \\
\hline Pau de Leite & Sapium glandulatum (Vell.) Pax. & 7,17 & 0,96 & 0,4212 & 1,24 & 6,33 & 1,12 & 3,32 \\
\hline $\begin{array}{l}\text { Guamirim } \\
\text { Miúdo }\end{array}$ & $\begin{array}{c}\text { Myrceugenia campestris (DC.) D. Legrand et } \\
\text { Kausel }\end{array}$ & 8,17 & 1,09 & 0,3229 & 0,95 & 6,50 & 1,15 & 3,19 \\
\hline Aroeira & Schinus terebinthifolius Raddi & 6,67 & 0,89 & 0,3694 & 1,09 & 5,83 & 1,03 & 3,01 \\
\hline Capoeirão & Turdus leucomelas & 8,83 & 1,18 & 0,2863 & 0,84 & 4,50 & 0,80 & 2,82 \\
\hline Maria Mole & Pisonia aculeata $L$. & 7,17 & 0,96 & 0,2260 & 0,66 & 6,67 & 1,18 & 2,81 \\
\hline Jacarandá Liso & Machaerium vestitum Vogel & 6,83 & 0,92 & 0,2456 & 0,72 & 6,17 & 1,09 & 2,73 \\
\hline Bugreiro & Lithraea brasilienses & 5,33 & 0,72 & 0,4007 & 1,18 & 4,67 & 0,83 & 2,72 \\
\hline Pereira & Platycyamus regnellii benth & 7,50 & 1,01 & 0,1589 & 0,47 & 6,50 & 1,15 & 2,62 \\
\hline Caúna & Ilex brevicuspis Reissek & 6,33 & 0,85 & 0,1723 & 0,51 & 6,17 & 1,09 & 2,45 \\
\hline $\begin{array}{l}\text { Guamirim } \\
\text { ferro }\end{array}$ & Myrcia arborescens $O$. Berg & 4,67 & 0,63 & 0,2931 & 0,86 & 4,33 & 0,77 & 2,25 \\
\hline Canela Branca & Nectandra membranacea & 4,17 & 0,56 & 0,3189 & 0,94 & 4,00 & 0,71 & 2,20 \\
\hline $\begin{array}{l}\text { Pessegueiro } \\
\text { Bravo }\end{array}$ & Prunus myrtifolia & 5,50 & 0,74 & 0,1554 & 0,46 & 5,50 & 0,97 & 2,17 \\
\hline$:$ & $:$ & $:$ & $:$ & $:$ & $:$ & $:$ & $:$ & $:$ \\
\hline$:$ & $:$ & $:$ & $:$ & : & $:$ & : & $:$ & : \\
\hline Total & & 745,83 & 100 & 34,001 & 100 & 565,39 & 100 & 300 \\
\hline
\end{tabular}

Além das espécies observadas na Tabela 1 e Tabela 2, encontram-se o guaraperé (Lamanonia ternata Vell.), canela guaicá (Ocotea puberula (A. Rich.) Nees), pessegueiro bravo (Prunus myrtifolia), vassourão-preto (Vernonia discolor), pereira (Platycyamus regnellii benth), camoatá (Cupania vernalis), caúna preta (Ilex sp. 2), vacum (Allophylus guaraniticus (A. St-Hil.) Radlk), nurcia (Myrcia sp. 2), farinha seca (Albizia hasslerii (Chodat) Burr), capororocão (Myrsine umbellata Mart.), vassourão-branco (Vernonia discolor (Spreng.) Less), cedro branco (Guarea guidonia (L.) Sleumer), açoita cavalo(Luehea 
divaricata Mart. et Zucc), imbuia (Phoebe porosa (Nees et Mart.) L. Barroso), canela preta (Nectandra megapotamica (Spreng.) Mez), dentre outras espécies com menor destaque, tendo sido encontrados número menor que um indivíduo por hectare.

Sendo as famílias que apresentaram maior riqueza de espécies foram Myrtaceae (18 espécies), Lauraceae (9 espécies), Aquifoliaceae (7 espécies), Fabaceae e Primulaceae (6 espécies cada uma). Ao passo que a densidade total observada no ano de 2000 foi de 798,34 ind./ha amostrados. Observou-se que as 20 espécies mais abundantes contribuíram com aproximadamente $74 \%$ em relação ao total da floresta. Dessas, seis espécies representaram mais de $46 \%$ da densidade total da floresta.

$\mathrm{Na}$ floresta como um todo, o guamirim (Myrcia sp.), com 87,67 ind./ha, foi a espécie mais abundante (10,98\%). Em seguida, destacou-se o sassafrás (Ocotea odorífera), com 80,67 ind./ha e $10,10 \%$, enquanto a erva mate (Ilex paraguarienses) foi a terceira espécie mais abundante da floresta, com 65,33 ind./ha e 8,18\%. Na sequência, apareceram as espécies: laranjeira brava (Gymnanthes concolor), com 53 ind./ha e 6,64\%, caingá (Myrcinhatschbachii sp.), com 42,50 ind./ha e 5,74\%, canela fedida (Nectandra lancolata), com 42,50 ind/ha e 5,32\%. Em um estudo realizado em Campo Belo - SC por Formento et al. (2004), observou-se como espécie mais abundante Lithraea brasilienses com 71 ind./ha, correspondendo a $13,41 \%$ do total de árvores.

Com relação às espécies menos abundantes, que representam cerca de $80 \%$ da composição florística da área, observou-se que agrupadas compõem cerca de $20 \%$ da abundância total da floresta (CORAIOLA;PÉLliCO NETTO, 2003). Das 98 e 99 espécies encontradas em 2000 e 2009, respectivamente, aproximadamente $74 \%$ da densidade foi representada por $20 \%$ do número total de 20 espécies, que caracterizaram a composição florística da floresta, enquanto as demais espécies, aproximadamente $80 \%$, representaram $26 \%$ da densidade total da floresta.

Nas Tabelas 1 e 2, foi possível observar que o grupo de espécies não identificadas apareceram entre as 20 mais abundantes, representando $4,95 \%$ e 1,17\% do total, respectivamente para os anos de 2000 e 2009. É importante destacar que tais indivíduos não foram identificados no momento em que foram incluídos no banco de dados, impossibilitando sua identificação posterior, muitas vezes em função da sua mortalidade no período.

Em 2009, a densidade total de indivíduos foi 745,83 ind./ha, representando decréscimo de 6,58\% em relação a densidade total de 2000 de 798,34 ind./ha. Esse fato pode ser explicado pela maior taxa de mortalidade na floresta em relação aos ingressos observados no período avaliado. Diferentemente do resultado encontrado neste trabalho, Sanquetta et al. (2001) observaram acréscimo de $6 \%$ em relação ao total de indivíduos em um período de 1995 e 1998 de um fragmento da mesma tipologia florestal em IratiPR.

As seis espécies mais abundantes da floresta em 2009 representaram mais de 49\% da densidade total. Observou-se, também, que as seis espécies mais abundantes em 2000 se destacaram também em 2009, apenas com mudança de posição entre o caingá (Myrcinhatschbachii sp.) e a laranjeira brava (Gymnanthes concolor). Com relação as 20 espécies mais abundantes, observou-se que pau de leite (Sapium glandulatum) e bugreiro (Lithraea brasilienses) fizeram parte das mais abundantes, entretanto, em 2009 foram substituídos por guamirim miúdo (Myrceugenia campestris) e pereira (Platycyamus regnelli Benth).

Com relação à dominância, em termos de área basal para todas as espécies amostradas em $2000 \mathrm{e}$ 2009 (Tabelas 1 e 2), observou-se pequeno aumento, de 32,5182 m²/ha em 2000 para 34,0008 m²/ha em 2009 , representando um acréscimo de 4,56\%. Tal acréscimo pode ser justificado apenas pelas taxas de crescimento das espécies, uma vez que a taxa de ingressos foi menor do que a taxa de mortalidade no período. Este resultado foi maior quando comparado com o encontrado por Sanquetta et al. (2001), que 
obtiveram aumento de $3,02 \%$, com taxa de ingressos maior que a mortalidade.

Tanto em 2000 quanto em 2009, a Nectandra lanceolata foi a espécie mais dominante da floresta, com 2,7348 $\mathrm{m}^{2} / \mathrm{ha}$, representando 8,41\% da dominância total em 2000 e 2,9117 $\mathrm{m}^{2} / \mathrm{ha}$ e $8,56 \%$ do total em 2009. Em 2000, destacou-se também a erva mate (Ilex paraguariensis), com $2,4251 \mathrm{~m}^{2} / \mathrm{ha} \mathrm{e} 7,46 \%$ do total, e o sassafrás (Ocotea porosa), com 2,2669 $\mathrm{m}^{2} / \mathrm{ha}$ e 6,97\% do total da floresta. Para 2009, essas espécies apareceram na sequência das mais dominantes, porém com ordem invertida. Ademais, a dominância do sassafrás (Ocotea porosa) correspondeu a $2,7151 \mathrm{~m}^{2} / \mathrm{ha}$ e $7,99 \%$, e a erva mate (Ilex paraguariensis) apresentou $2,6288 \mathrm{~m}^{2} /$ ha e $7,73 \%$ do total.

As espécies Nectandra lanceolata, Ilex paraguariensis, Ocotea porosa e Myrcia sp. Representaram, aproximadamente, 30\% da área basal da floresta nos dois períodos analisados, e, juntamente com as seis espécies subsequentes mais dominantes nos dois períodos estudos, representaram cerca de $60 \%$ da área basal total da floresta.

Rondon Neto et al. (2002), estudando um fragmento de Floresta Ombrófila Mista, em Criúva RS, encontrou em média uma área basal de 45,01 m²/ha, sendo a espécie mais dominante a Araucaria angustifolia. Rode et al. (2010), na Floresta Nacional de Irati - PR, obteve uma área basal média de 29,9 $\mathrm{m}^{2} / \mathrm{ha}$, com a Araucaria angustifolia, novamente como a espécie mais dominante da floresta. Comparando esses resultados com os encontrados no presente trabalho, observou-se que a área basal de $32,5182 \mathrm{~m}^{2} / \mathrm{ha}$ em 2000, e 34,0008 m²/ha em 2009, pode ser considerada como um valor médio para esse tipo de floresta. Com relação a presente pesquisa, cabe ressaltar que a Araucaria angustilia não consta entre as espécies mais dominante da floresta, ocupando apenas a quinta colocação entre as espécies dominantes, tanto em 2000 quanto em 2009.

Com relação a dominância, cabe destacar que as espécies Araucaria angustifolia e Cedrela fissilis, apesar de não estarem entre as 10 espécie mais abundantes, apareceram entre as 10 mais dominantes da floresta, com 1,6996 m²/ha (5,23\%) e 1,5184 m²/ha (4,67\%) em 2000, respectivamente, e 1,9491 $\mathrm{m}^{2} / \mathrm{ha}$ $(5,73 \%)$ e $1,5147 \mathrm{~m}^{2} / \mathrm{ha}(4,45 \%)$ em 2009 . Isso deve-se ao alto valor da madeira dessas espécies, e por isso muito exploradas no passado.

Corroborando com Sanquetta et. al. (2001), o qual ressalta que analisar as espécies apenas pelos parâmetros de densidade, dominância ou frequência isoladamente, em termo de perspectivas de manejo, compromete a avaliação pois nem sempre as espécies apresentam todos os índices desses parâmetro em níveis altos dentro do povoamento.

De acordo com os valores de frequência absoluta e relativa (Tabelas 1 e 2), observou-se que, tanto em 2000 quanto em 2009, a espécie Myrcia Sp. apresentou a maior frequência na floresta, de 8,75\% e $10,26 \%$, respectivamente. A segunda espécie mais frequente na floresta, com valores próximos aos encontrados para a Myrcia Sp., foi o sassafrás (Ocotea odorífera), com 8,36\% de frequência em 2000 e $9,20 \%$ em 2009, seguida da erva mate (Ilex paraguariensis), com frequência de 7,26\% em 2000 e de $6,96 \%$ em 2009.

As espécies apresentaram distribuição irregular nas parcelas. Algumas apareceram isoladas, outras ocorreram em grupos, ou ainda concentradas apenas em locais da área amostrada. Isso se deve, também, a grande variedade de espécies encontrada na área em estudo (98 espécies em 2000 e 99 espécies em 2009), sendo maior que os valores encontrados por Sanquetta et al. (2001), os quais observaram cerca de 65 espécies em 1995 e 66 espécies diferentes em 1998.

De acordo com os valores observados nas Tabelas 1 e 2, observou-se que o guamirim (Myrcia sp.) foi a espécie com o maior valor de VI, tanto em 2000 como em 2009, com 26,45 e 30,02, respectivamente (aumento de 13,50\%). Em segundo lugar, apareceu o sassafrás (Ocotea odorífera), com 25,44 (8,48\%do total) em 2000 e 28,07 (9,36\% do total) em 2009. Em seguida, observou-se a erva mate (Ilex 
paraguariensis), com 22,90 (7,63\% do total) em 2000 e 22,33 (7,44\% do total) em 2009. Com base nos resultados, pode-se destacar que houve redução de 2,49\% no valor de importância de Ilex paraguariensis, devido ao baixo ingresso obtido pela espécie, quando comparada com outras de maior VI.

Dentre as 20 espécies com maior VI, destacou-se a Araucaria angustifolia, que, apesar de apresentar baixos índices de densidade e frequência, com 1,61\% e 1,52\% em 2000 e 1,74\% e 1,65\% em 2009, respectivamente, apresentou valor de importância entre as 10 mais representativas, devido principalmente a sua alta dominância. Assim como constatado por Albuquerque (2009), em que as espécies tradicionais de um Sistema Faxinal apareceram em proporção reduzida de indivíduos, como é o caso do pinheiro (Araucaria angustifolia), com apenas um indivíduo, ocupando a $30^{\underline{a}}$ posição em relação a densidade.

Quando analisada a alteração entre as cinco espécies mais importantes, observou-se aumento no valor importância absoluto (VI), de 109,27 em 2000 para 116,62 em 2009. Sawcsuk (2009), em um estudo realizado em Floresta Ombrófila Mista, encontrou valores maiores aos desta pesquisa, destacando que o aumento relativo foi de $0,20 \%$ no período estudado.

\section{CONCLUSÃO}

Myrcia sp. foi a espécie com o maior índice de valor de importância, nos dois períodos analisados, sendo a espécie mais característica da floresta, com um VI de 26,45 em 2000 e 30,02 em 2009.

As espécies com maiores densidade são: Myrcia sp., Ocotea odorifera, Ilex paraguariensis, Gymnanthes concolor e Mycinhatschbachii sp. nos anos de 2000 e 2009, que juntas representam mais de $40 \%$ da densidade total do fragmento de Floresta Ombrófila Mista.

As espécies Nectandra lanceolata, Ocotea odorifera e Ilex paraguariensis apresentam-se, tanto em 2000 quanto em 2009, com as mais dominantes da floresta, e juntas com a Myrcia sp. e a Araucaria angustifolia representam cerca de $38 \%$ da dominância total.

Cabe destacar ainda que, a Araucaria angustifolia, espécie considerada a mais importante e característica dessa tipologia florestal, a Floresta Ombrófila Mista, nessa área pesquisada, em Fazenda Rio Grande - PR, é apenas a $12^{\circ}$ no índice de importância em 2009 e o $9^{\circ}$ lugar em 2009.

Para a floresta como um todo, observa-se que ela possui alta densidade de indivíduos no primeiro ano de análise (2000), se mantendo alto em 2009, mesmo com a redução no número de indivíduos, sendo resultado do estágio sucessional secundário da floresta. Fato este que não ocorre com a dominância dos indivíduos, uma vez que a taxa de crescimento indivíduos é maior do que a mortalidade da floresta. Destaca-se também que mais de um terço do VI da floresta, nos dois períodos analisados, são composto por apenas cinco espécies.

\section{AGRADECIMENTO}

Ao projeto PELD por ter cedidos os dados e pelo financiamento dos custos para a realização desse trabalho.

Ao CNPq pela bolsa/PIBIC concedida para a realização do trabalho. 


\section{REFERÊNCIAS}

ALBUQUERQUE, J. M. de. Florística, estrutura e aspectos físicos de uma Floresta Ombrófila Mista em sistema faxinal no município de Rebouças, Paraná. 93f. Dissertação (Mestrado) - UNICENTRO. Irati, 2009.

CORAIOLA, M. Caracterização estrutural de uma Floresta Estacional Semidecidual localizada no Município de Cássia - MG. 196 f. Dissertação (Mestrado) - UFPR. Curitiba, 1997.

CORAIOLA, M.; PÉLLICO NETTO, S. Análise da estrutura horizontal de uma Floresta Estacional Semidecidual localizada no município de Cássia - MG. Revista Acadêmica: ciências agrárias e ambientais. Curitiba, v. 1, n. 2, p. 11-19, 2003.

FORMENTO, S.; SCHORN, L. A.; RAMOS, R. A. B. Dinâmica estrutural arbórea de uma floresta ombrófila mista em Campo Belo do Sul, SC. Revista Cerne. Lavras, v. 10, n. 2, p. 196-212, 2004.

GALVÃO, F.; KUNIYOSHI, Y.S.; RODERJAN, C.V. Levantamento fitossociológico das principais associações arbóreas da Floresta Nacional de Irati - PR. Revista Floresta, Curitiba, n.1/2, p.30-49, 1989.

RODE, R.et al. Estrutura Horizontal da comunidade arbórea sob um povoamento com Araucaria angustifolia e uma Floresta Ombrófila Mista. Revista Pesquisa Floresta Brasileira. Colombo, v.30, n. 64, p. 347-361, 2010.

RONDON NETO, R. M.et al. Análise florística e estrutural de um fragmento de Floresta Ombrófila Mista Montana, situado em Criúva, RS - Brasil. Revista Ciência Florestal. Santa Maria, v. 12, n. 1, p. 29-37, 2002.

SANQUETTA, C. R.et al. Dinâmica da estrutura horizontal de um fragmento de Floresta Ombrófila Mista no Centro-sul do Paraná. Revista Ciências Exatas e Naturais. Irati, v. 3, n. 1, p. 43-57, 2001.

SAWCZUK, A. R. Florística e estrutura horizontal no período 2002-2008 de um fragmento de Floresta ombrófila Mista no Centro-sul do estado Paraná. 139f. Dissertação (Mestrado) UNICENTRO. Irati, 2009.

STEPKA, T. F. Modelagem da Dinâmica e Prognose da Estrutura Diamétrica de uma floresta Ombrófila Mista por meio de Matriz de Transição e Razão de Movimentação. Irati: 2008. 138 f. Dissertação (Mestrado em Ciências Florestais). Universidade Estadual do Centro-Oeste.

VALÉRIO, Á. F.et al. Análise da composição florística e da estrutura horizontal de uma floresta ombrófila mista Montana, município de Irati -PR. Revista Acadêmica: Ciências agrárias e ambientais. Curitiba, v. 6 , n.2, p. 134-147, 2008. 